\title{
A Study of Behavioral Training as Talent Management Strategy in Organisations
}

\author{
Poonam Jindal ${ }^{1, *}$, Mohsin Shaikh ${ }^{2}$ \\ ${ }^{1}$ Vignana Jyothi Institute of Management \& Honorary Treasurer-ISTD, Pune University, Hyderabad Chapter, Hyderabad \\ ${ }^{2}$ Department of Management Studies, SKN College of Engineering, Pune \\ *Corresponding Author: poonam.j@vjim.edu.in
}

Copyright $(\underset{0}{ } 2015$ Horizon Research Publishing All rights reserved.

\begin{abstract}
The current paper aims to investigate the importance of behavioral training and development in organizations for talent management. The importance of technically strong employees is always there in organizations, but managing people is not same as managing technology. If people are motivated to work, they can use their technological strengths for the companies' betterment. Because of the lack of behavioral skills they often lack leadership skills. This paper is based on extensive literature review, to understand the importance of Behavioral Training as Talent Management strategy in Organizations in current scenario. Now organizations need leaders not only good employees, keeping this in mind organizations are giving more importance to behavioral skill training to develop managers as leaders. Behavioral skills training helps you to understand who you are and what you want to be. Behavioral training aims at developing skills for self-regulation of brain activity. The importance on behavioral training is increasing worldwide as Prof Buddhadip Mukharjee of Indian Institute of Social Welfare \& Business Management (IISWBM) shared his expertise on "Organizational Behavior" to working executives of UK, MALAYSIA, SOUTH AFRICA, MIDDLE EAST, SINGAPORE \& INDIA by interactive classes through TeamViewer. In today's time survival of the business is not the only requirement, it should have the sustainable growth also in global economy and for that companies are working on developing, maintaining and retaining the talent through talent management strategies. Training is one of the many strategies companies are working on and behavioural training is getting more concerned because its not your ability but your attitude which make you successful in job. Behavioral skills are the requirement not only for survival but for the balance of personal and professional life too. Today's stressful life of employees is being constraint for their best performance in job, for this reason too Organizations are giving importance to Behavioral Skills Training not only for managerial people but for all employees in organization. Many Research papers have put the light on the behavioral training and how organizations are conducting these training. Here in this paper the light has thrown on the importance of behavioral
\end{abstract}

training for talent management in organizations. Companies are understanding the importance of these trainings that's why they are more concerned about program like mentoring and coaching which can be the talent management strategy for companies. "If you think about the leaders with whom people most want to work in an organization they probably have this ability to exude upbeat feelings. It's one reason emotionally intelligent leaders attract talented people- for the pleasure of working in their presence." Daniel Goleman The New Leaders These lines of Daniel reflect the importance of behavioral skills for a leader or manager.

Keywords Behavioral Skills, Management Development Programmes, Motivation, Emotional Intelligence, Work life Balance, Leadership

\section{Background}

In a 1998 article, MCKINSEY QUARTERLY introduced the term "War of talents" to show the fact that need for attracting, retaining and developing talented employees was emerging as the basis of competitive growth for any industry. The main focus and impact on the organization is to identify, develop and redeployment of talented employees, as they are smaller group, and easy to measure, and critical to the organization's success. At the end of the day companies can bet on the people not on the strategies ( Larry Bossidy of Allied Signals). The reasons for this war are not difficult to find. One reason is talented manpower is becoming a scarce resource and to get that talent companies are trying everything to attract the best talent available in market through poaching or promising the best compensation package, stock options, and big bonuses etc. Next difficulties for companies are to manage and retain that talent. Companies are not able to manage the skills of employees or if not able to utilize them properly, employees are at risk of becoming discontented or uncommitted towards their job or work. By designing career paths, planning succession and investing heavily in employee 
development, the companies are hoping to win back the loyalty and commitment of its workforce. People frequently switching their jobs and then it's difficult to retain the talent but companies cannot afford to lose their talent and investing heavy cost in recruitment continuously. One main reason of leaving job given by professionals is because their senior manager does not understand the psychology of work satisfaction. This problem is about the behavior and not about the knowledge of the employees.

Until the late 1980s, business school curricula emphasized the technical aspects of management, focusing on economics, accounting, finance and quantitative techniques. Course work in human behavior and people skills received relatively less attention. Same with the companies, they were also not putting force on human skills in those days. Slowly the importance of understanding human behavior increased for Organizations too. Developing managers' interpersonal skills also helps organizations attract and keep high performing employees. We have come to understand that in today's competitive and demanding workplace, managers can't succeed on their technical skills alone. They also have to have good people skills. Every organization in today's world invests in behavioral training. It does seem like organizations have woken up to realize the importance of key behaviors and their relevance at every stage of the employee life cycle. The significance of training in general and behavioral training in particular is now concerned for the Organizations to manage talent. Leaders more than anything else need to have a certain character. Hence every training session that deals with leadership has to deal with character building. Unfortunately many Organizations do not pay much attention in bringing out and building the best Interpersonal skills in their employees. It is very important that attention be given towards behavioral skills and soft skills such that a balance of technical competency and behavioral skills is maintained which is an important criteria for any Organization. Behavioral skills like motivation, leadership, communication skills, team spirit and self-management, stress management, work life balance, conflict resolution, have noticed a marked transition in the last few years from being 'good to have' to be a 'pre-requisite'. The shift in perception is not without reason. Organizations across the globe have realized that employees leave organization many times not because of the work but because of the boss. It shows the problem relies on interpersonal issues and that is because people are not having proper behavioral skills. Today's employee is empowered and intelligent, and no longer can you expect over bearing, high pressure management tactics to improve performance. In the modern work place, managers are discovering that they must work in partnership with their employees, providing them with the knowledge they need for completing the task. For accomplishing goals of the organization as well their own goals employees need not only work skills but behavioral skills as well are required. Having a positive behavior, even if you're not passionate about what you do, will make your co-workers want to work with you. So retaining and managing such talent require more weight on behavioral trainings.

\section{Purpose}

The purpose of the paper is to clear the concept of Behavioral Trainings and Talent Management and importance of behavioral training in Organizations for talent management.

\section{Behavioral Skills \\ - the action, reaction, or functioning of a system, under normal or specified circumstances \\ - manner of behaving or conducting oneself}

While successful managers must possess a high level of expertise in technical, human, and conceptual skills, it is also true that each skill will vary in importance according to the level at which the manager is located in the organization. Generally, technical skills become least important at the top level of the management hierarchy, replaced with a greater emphasis on conceptual skills. Technical skills are most pronounced at lower levels of management because first-line managers are closer to the production process, where technical expertise is in greatest demand. Human skills are equally necessary at each level of the management hierarchy. Conceptual skills are critical for top managers because the plans, policies, and decisions developed at this level require the ability to understand how a change in one activity will affect changes in other activities. So generally skills related with Human and Conceptual skills come under Behavioral skills.

Importance of Behavioral Training: "Organizations looking to put their leaders through the grind in the current business environment are investing heavily on training, augmenting budgets by as much as $87 \%$ this year."

\section{(Top Leadership Takes a Few Survival Lessons, The Economic Times)}

\section{Direct Impact of Behavioral Trainings:}

Morale: Training and Development helps in improving the morale of the work force. Training and Development helps in developing leadership skills, motivation, loyalty, better attitudes, and other aspects that successful workers and managers usually display. Training and Development demonstrates a commitment to keeping employees on the cutting edge of knowledge and practice.

Motivation: The success of every business organization depends fundamentally on the motivation of the employees. In basic terms, motivation is an inner drive that compels behavior. In current scenario getting motivation from outside is really difficult for the employees, and then we concentrate on the intrinsic motivation. Training programmers help employees to develop that intrinsic motivation through different motivational training program. How to increase your internal motivation and develop enthusiasm for work 
can be developed by training programmers. That's the reason organizations are giving importance to motivational trainings to get a satisfied and internally motivated employee.

Cross cultural work environment is the other reason for giving importance to behavioral Trainings. Coping with the changes related with the people around you is very important for the employees. Different training programs which help employees to understand the cultural difference in employees from the same country or other countries help them to work with them easily.

Stress: Stress is the other important reason for providing behavioral training to employees. There are several reasons of stress at work place which can be related from your boss to your subordinates' behavior, no clarity in work and sometimes your personal life too. How to deal with the issues who can create stress in employees' life are the other behavioral training programs.

Conflict Management Skills: Employees need to understand what conflict is and be equipped with techniques to recognize when they are getting into conflict and to control their behavior more effectively in those difficult situations. They should learn tools to help themselves and others in conflict to explore the issue honestly and constructively. Through Behavioral Training Employees can learn conflict management.

Work life balance: training is another much discussed topic in current workplaces. As now employers and management is clear that unlike baby boomers and Gen X, Gen $\mathrm{Y}$ gives equal importance to their personal life as professional. They cannot separate their personal life from their professional life. To give equal significance to both trainings are available in corporate for the employees.

Leadership: Only technical knowledge cannot make you a leader of people, people knowledge is something required to every manager. Now all companies don't want only technically experts but people with the behavioral qualities, who can be proved great leaders at work place. As Goleman has given importance to the emotional intelligence for new generation leaders, organizations are also putting emphasis on behavioral qualities like emotional intelligence.

\section{Talent and Talent Management Concept:}

The "war for talent" was officially launched in 1997 when McKinsey \& Company, America's largest and most prestigious

Management- consulting firm published as, "better talent is worth fighting for" (Chambers et al.,1998: 45). By collecting data from a year-long study of 77 companies from various industries and nearly 6000 managers and executives, and supplemented by case studies of 20 companies regarded as being good in talent. According to McKinsey, talent is ... "the sum of a person's abilities... his or her intrinsic gifts, skills, knowledge, experience, intelligence, judgment, attitude, character and drive. It also includes his or her ability to learn and grow" (Michaels et al., 2001: xii). In the popular book, Topgrading, Bradford Smart (2005: xviii) defines talent as "A players are the top $10 \%$ of talent available in all salary levels, best of class." Robertson and Abbey also focus on the best and the brightest, in Managing Talented People (2003).

In contrast to the definitions above, talent has become a substitute for the entire workforce in many organizations and a large number of companies do not even know how to define talent (Economist, October 2006). Professor and HR guru David Ulrich takes a holistic view with his definition: talent=competence commitment contribution (Ulrich, 2006). In his formulation, competence means that individuals have the knowledge, skills and values that are required for today and tomorrow. Commitment means that employees work hard, put the time in to do what they are asked to do, giving their discretionary energy to the firm's success. Contribution means that they are making a real contribution through their work finding meaning and purpose in their work. Using Ulrich's terms, the talent war represents the drive to find, develop, and retain individuals, wherever they are located in the world, who have the competencies and commitment needed for their jobs and who can find meaning and purpose in their work. His definition shows that more than technically strong the employees should have the attitude and behavior to be talent and organizations understand that now.

Michael Armstrong characterizes talent management as the "war for talent". He claims that this definition downplays the role of the talent which is already in the company. The elements are identified within talent management are attraction, retention, motivation and engagement, development, and succession planning. The main aim is to "develop and maintain a talent pool consisting of a skilled, engaged and committed workforce."

You cannot ignore the fact that the most dynamic part of any business is Man. Managing man is the task for all managers and employers. And this is the responsibility of the management to plan how to take work from the people in such a scenario when nothing is permanent except change. Everything is changing so fast that what we are learning today may not be helpful for next years' assignments. Which improves continues requirement not only for technical training but as well for behavioral training too.

\section{Methodology}

This paper is based on the rigorous literature review from different articles in newspaper, journals and companies' details on their training programmes on behavioral skills.

\section{Literature Review}

There is literature available on talent management and training as one of the strategies for talent management, but there is no direct literature available on the importance of behavioral training in talent management. But studies show that this is the attitude and behavior of the people which help them to perform well and to be committed for the work. 
Talent management defined in literature:

Collings and Mellahi (2009) proposed a definition for TM emphasizing its strategic aspects: Activities and processes that involve the systematic identification of key positions which differentially contribute to the organization's sustainable competitive advantage, the development of a talent pool of high potential and high performing incumbents to fill these roles, and the development of a differentiated human resource architecture to facilitate filling these positions with competent incumbents and to ensure their continued commitment to the organization.(p. 304)

Collings and Mellahi (2009) developed a theoretical model of strategic TM. In their model they define how the role of HR effects the firm's performance, and to develop and utilize internal talent, an organization should recognize the critical positions related to its competitive growth. Then according to the requirement of those pivotal positions the high potentials and high performers should be developed or recruited. These organizational efforts in HR architecture are proposed to empower talent to retain work motivation, organizational commitment, and extra-role behavior, which results in justifiable performance in the organization.

The development aspect of talent management talks about the training and development strategy, but the main focus of training will be to develop that commitment and motivation within employees.

Results of research show that an employee's degree of emotional fit is positively related to his/her psychological engagement at work with regards to connection with others and connection with work, but not task and role performance. In terms of connection with others, emotional fit was positively related to commitment and negatively related to surface acting. As for the connection with work domain, emotional fit was negatively related to psychological withdrawal behaviors and intention for turnover. (Emotional Fit in the Workplace: Its Psychological and Behavioural Outcomes, Hakan Ozqelik, July 2004). It shows that the importance of behavior is there for the retention of employees.

In an Article "Importance of Corporate Training and Development” by Jagtap Pal Singh, Director of Technology, Cybage Published in December 7, 2006- The Indian Express, Pune

"Cybage's training and development department is divided in three categories - technical, cultural and behavioral. Each division is headed by a senior manager and progress is very closely monitored with respect to the goals set by CEO, Arun Nathani. By having effective and efficient training plan for technology an organization is covered for probably $30 \%$ of training and development need but it is still less than even one third. Over a period of time we have realized it is employee's attitude that matters a lot. A person may be wonderful technically but if he is a misfit in a team, delivery becomes very challenging. Changing someone's behavior is a development process that takes time but without that, technical training remains unutilized to a great extent. Cybage conducts need analysis which is very similar to competency mapping and observations are made about employees behavioral patterns. We focus equally on technical and behavioral training and cultural training is at third place and it will remain that way for long due to our unique business model of predominantly offshore. I personally feel an organization without effective training and development is more like a living being without required nutrition and a low par performance or even slow death is inevitable."

The competencies need to be used to align and integrate activities and processes with regard to talent management in each area in order to maximize the synergy of organizational functions, as well as performance excellence of talent (Heinen \& O'Neill, 2004). The role of training here is to identify the competencies and provide effective inputs to develop the abilities of talent. Marquardt et al. (2004) introduced six global competencies as special abilities for global employees: cultural self-awareness, global perspectives, language, tolerance for ambiguity and differences, cultural flexibility, and strong communication skills. If we see closely the all competencies are reflection of behavior of employees.

Global talent who work with people from different cultures and backgrounds need cross-cultural training because the training helps employees not only obtain knowledge, skills, and attitudes needed for competing assigned job(Osman-Gani \& Zidan, 2001) but also adapt to a different cultures of different countries, which is essential for a successful completion of international task (DeSimone et al., 2002). Despite much research on cross-cultural training, McLean (2006) pointed out that many training programs dealing with cross-cultures are still "atheoretical" (p. 211) and emphasize mainly what to do or not to do. Relying only on cognitive information and linguistic skills can be less effective for people who are preparing for global tasks (Guthridge \& Komm, 2008; McLean, 2006). To make a cross-cultural training program effective, trainees should have learning experiences in terms of acculturation and be encouraged to have a "cultural milieu" (Marquardt et al., 2004, p. 44) in the program (Stanek, 2000). So training has an important role in managing talent in global scenario.

Diversity training, coaching, and mentoring programs are other ways of developing both knowledge and attitudes of employees who are working with diverse colleagues (McGuire, 2011). Cultural facilitation and mediation may reduce the incidences of prejudice and misbehavior in the first meeting (McLean, 2006). When individuals are willing to learn about and accept differences, they can generate a synergic effect and provide better performance (Ely \& Thomas, 2001). Interpersonal problems can also be addressed by clarifying goals, roles and responsibilities, or procedures and processes (Burke, 2011).

In one Article "The Importance of Training for Call Center Executives". By Martin Bastian, $\mathrm{Sr}$. Executive( Training \& Development), IPSEL, he mentioned- 
"Many Organizations these days are stressing more on the importance of Customer satisfaction and have started introducing Satisfaction performance Indexes such as CSAT (Customer Satisfaction Index) and FTR ( First Time Resolution ). Working in such an Environment that is always demanding and continuously changing can be very stressful if proper training has not been provided to such people who manage huge volumes of customer related data and customer interactions. IPSEL a leading name in Training \& Development has chalked out a large number of programmers for behavioral skills training-presentation skills, team building, personal grooming, attitudinal change, cross-cultural management, time management, stress management and consulting skills. "Out of these personal grooming and cross-cultural management are very significant. The first because it trains one in personal hygiene, conversational skills, telephone skills, etc. Cross cultural training helps the consultant move from a "mine" is the only culture in the world to a multi-cultural outlook."

\section{An Article by author - P. Mane \\ http://www.rishabhsoft.com/blog/importance-of-behavior al-training}

"We have enough training structured to improve the 'mechanical' or should I say, 'technical' aspects of a professional personality. However, as research upon research has concluded, it is not the 'technical' but the 'psychological' or 'behavioral' aptitude that gets the better of an individual in crunch situations. 'This' is the crucial aspect where our 'Technically' near-perfect individuals lack in the modern era. This attribute especially applies to modern day managers who have to cope with a generation of employees who are equal if not more ambitious than their managers.

In such a dynamic scenario, behavioral training can empower managers to leverage this positive kinetic energy of modern day Indian youth. Assertiveness, handling conflicts, creating Win-Win situations, accommodating changes, flexibility and dynamic approach are some of the areas where a lot of focus needs to be channelized. Resources at the end of the day especially in an IT industry are human beings and they cannot be programmed to work in a particular manner. The algorithms for getting work done from these resources are complex involving emotional, behavioral and attitudinal competence."

This article clears the role of training and specifically role of behavioral training for managing talent in organizations.

In one recent Article in The Economic Times, 17 Sep, 2013 “Top Leaders takes a Few Survival Lessons', Companies hike training budgets by as much as 87\% while training institutes see a huge spike in demand, by Anumeha Chaturvedi.

Here she reflects the importance of Behavioral Training by presenting view as "CEOs find it difficult to manage change and a lot of these programmes are also about enhancing their emotional strength, apart from from cognitive and technical abilities," says Nishchae Suri, partner and head of the people and change practice at KPMG.

At another Indian FMCG company Emami, the senior management has been trained in transactional analysis and people-centric leadership over the past year. It's training budget for this year have seen a major jump, says Harsha V Agarwal, director.

"Companies are looking at training leaders on ethics, integrity, succession planning, and business strategies," says Pallavi Jha, chairperson and managing director of Dale Carnegie Training India.

"Managing self, leading others and leading the organisations are critical aspects of training, but the emphasis is much more on the later in a slowdown," says Anurag Aman, head, leadership organization and performance practice at Mercer India.

These are few views points of experts from industry who feel that there is always an importance for behavior training for managing talent and developing next level of talent

\section{Model of Talent Management and Importance of Behavioral Training in that Model}

Talent Management is as defined in many literatures, process of attracting, hiring, developing and retaining the talent within organization. In the process of development different training programmes help to develop the best people in organization as leaders and managers. Companies are not only looking only for the best talent but employees who can be leaders in future and can develop a pool for future talent requirements. Here the development of only technical roles or competencies is not important but the behavioral aspects of personality and competencies are more crucial for performing well and staying with the company. Behavioral training programs on Emotional intelligence, proper cultural sensitivity, behavior in cross-cultures and leadership development for future leaders in organization work as strategy for the management of this talent. And this proper behavioral training helps to get the appropriate behavior fit for the culture of organization and gives a comfort to employees to stay in that environment. The results of such developmental programmes will be the increased motivation level of employees, more committed for the work and culture, engaged and it will help in retaining the best fit people for the organization. And the ultimate objective of organization that is the improvement in performance of the employees will be fulfilled. 


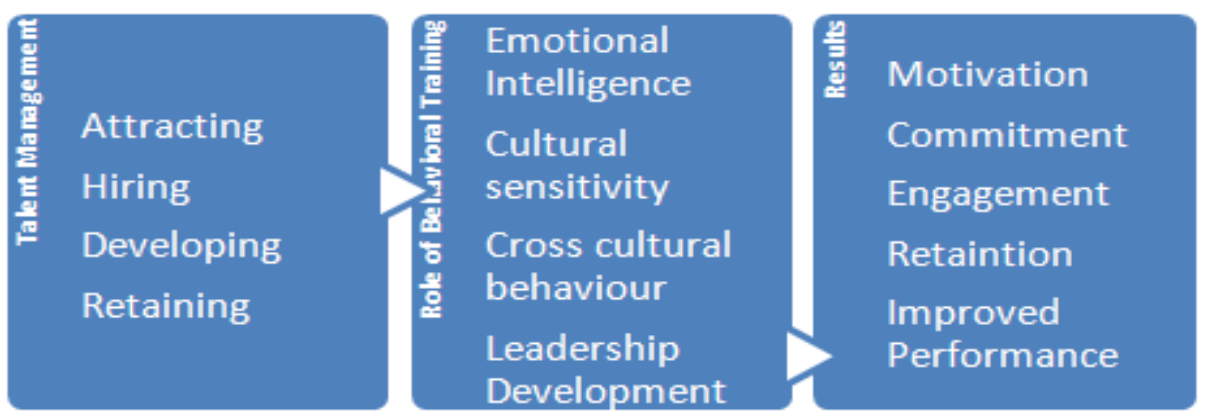

\section{Findings}

The role of human behavior is viewed an important factor of performance by many researchers due to its quick response towards any change. Toxic behavior spoils the performance of individuals and co-workers. People many times are not demotivated because of the work they do but because of the people they are working with. So, there is dire need to understand the human behavior at work and manage it accordingly. Cross-cultural competence is pre-requisite for global leaders and managing diversified behaviors in multinational companies is mandatory requirement for global talent management. Articles by experts and many other literature sources in fields explain the importance of behavioral training in Organizations for managing the talent. Organizations are putting more emphasis on behavioral trainings, as only technically strong people cannot run or make an organization successful. People with people's skills are required to run an organization successfully. So this is the urgency for Organizations to understand the importance of the behavioral changes through trainings and make them suitable for the work environment. Organizations are realizing the importance of behavioral training that can be analyzed by these articles which are reflecting their point of view about the importance of behavioral training. There is a scope of future research in this field with empirical data to find out the relationship of behavioral training and talent management.

\section{REFERENCES}

[1] Bhatnagar, J. (2008). Managing capabilities for talent engagement and pipeline development. Industrial \& Commercial Training, 40(1), 19-28.

[2] Collings, G. D., \& Mellahi, K. (2009). Strategic talent management: A review and research agenda. Human Resource Management Review, 19, 304-313.

[3] Covey, S. (1990). The Seven Habits of Highly Effective People. New York: Simon and Schuster.

[4] Goleman, D. (1995). Emotional Intelligence: Why It Can Matter More Than IQ. London: Bloomsbury Publishing Plc.

[5] Goleman, D. (1998). Working With Emotional Intelligence. London: Bloomsbury Publishing Plc.
[6] Goleman, D. (2002). The New Leaders. Time Warner Paperback.

[7] Guthridge, M., \& Komm, A. (2008). Why multinationals struggle to manage talent. The McKinsey Quarterly, pp. 10-13.

[8] Heinen, J. S., \& O'Neill, C. (2004). Managing talent to maximize performance. Employment Relations Today, 31(2), $67-82$.

[9] "Importance of Corporate Training and Development". Jagtap Pal Singh, Director of Technology, Cybage. Published in December 7, 2006- The Indian Express, Pune

[10] Marquardt, M., Berger, N., \& Loan, P. (2004). HRD in the age of globalization. New York, NY: Basic Books.

[11] McGuire, D. (2011). Diversity and HRD. In D. McGuire \& K. M. Jørgensen (Eds.), Human resource development: Theory and practice (pp. 172-180). Thousand Oaks, CA: Sage.

[12] McLean, G. N. (2006). Organization development: Principles, processes, performance. San Francisco, CA: Berrett-Koehler.

[13] McLean, G. N. (2010, October 28). TM: A new concept or repackaging of existing concepts? Should HRD even be involved? In Proceedings of the 2010 international conference on human resource development (Opening Keynote Presentation, pp. vii-xii) International HRD Conference, National Taiwan Normal University, Taipei, Taiwan.

[14] Michaels, E., Handfield-Jones, H., \& Axelrod, B. (2001). The war for talent. Boston, MA: Harvard Business School Press.

[15] "Millennials Will Need Soft Skills to Get Ahead" by Dan Schawbel, The Economic Times on 6th Sept 2013

[16] Osman-Gani, M. A., \& Zidan, S. S. (2001). Cross-cultural implications of planned on-the-job training. Advanced in Developing Human Resources, 3(4), 452-460.

[17] Robinson Stephen P., Judge Timothy A., Vohra Neharika. (2013), 15 $5^{\text {th }}$ Edition, Pearson Education, Inc.

[18] “Top Leadership Takes a Few Survival Lessons”. Anumeha Chaturveda, The Economic Times, 17th Sept, 2013

[19] "The Importance of Training for Call Center Executives". Martin Bastian, Sr. Executive (Training \& Development), IPSEL, An article by author - P. Mane

[20] http://www.rishabhsoft.com/blog/importance-of-behavioral-t raining

[21] http://dictionary.reverso.net/english-definition/behavioral $\% 2$ 0skills 